\title{
Construction Considerations for Low-Cost Earth Brick Shells
}

\author{
"Ryan Anthony Bradley', Mitchell Gohnert' and Ivanka Bulovic²
}

\begin{abstract}
Published online: 31 August 2018
To cite this article: Ryan Anthony Bradley, Mitchell Gohnert and Ivanka Bulovic (2018). Construction considerations for lowcost earth brick shells. Journal of Construction in Developing Countries, 23(1): 43-60. https://doi.org/10.21315/jcdc2018.23.1.3.

To link to this article: https://doi.org/10.21315/jcdc2018.23.1.3

Abstract: Earthen shells are typically designed as pure-compression structures; however, some issues associated with construction practice, fixity, and certain actions (i.e., loading), which induce tensile stress, are often overlooked. Thus, cracking is not uncommon in unreinforced earthen shells. Cracking is particularly undesirable in these shells due to issues associated with the durability of earthen building materials. Moisture, in particular, may significantly compromise the strength and longevity of earthen masonry. In this paper, conventional and contemporary techniques utilised for the construction of earthen shells are reviewed. Furthermore, construction concerns with several methodologies are identified based on case study investigations and lessons learnt from several shells designed, built and monitored by the authors. An important finding is that fixity generated during construction with formwork can lead to significant cracking in earthen shells.
\end{abstract}

Keywords: Earth-brick shells, Low-cost housing, Construction considerations

\section{INTRODUCTION}

Masonry thin shells may be an efficient and versatile solution to the housing problem affecting many developing countries. The major advantage of many shell forms is that expensive forces, such as shears and moments, are limited in extent and magnitude. These structures typically require only minimal amounts of materials when compared with standard housing structures (i.e., rectangular plan structures comprising cement block or clay brick masonry walls and a standard roof). Furthermore, some shells, such as reinforced concrete domes, have shown the ability to resist extreme loading conditions (i.e., hurricane force winds) (Wilson, 2005). Thus, structurally efficient shell forms, in conjunction with sustainable materials, are a superior solution in terms of strength, economy and cost to the consumer.

However, the adoption of earthen shells for low-cost buildings requires careful attention by designers and builders to ensure safe and durable structures. A fundamental consideration when designing unreinforced earthen shells is that the thrust line (or compressive force resultant) remain within the middle-third of the shell (thus ensuring no tensile stresses). This requirement is due to the inherent weakness of unreinforced earthen materials in tension and flexure. Due to this weakness, the development of even minor tensile stresses may lead to cracking damage. The sources of cracking in masonry shells are numerous; however, the construction methodology and quality of workmanship may have a significant influence on the stress distribution, and the potential for cracking, within these structures.

\footnotetext{
ISchool of Civil and Environmental Engineering, University of the Witwatersrand, Private Bag 3, PO Wits, Johannesburg, 2050, Gauteng, SOUTH AFRICA

${ }^{2}$ Mott MacDonald PDNA, 25 Scott Street, Johannesburg, 2090, Gauteng, SOUTH AFRICA

"Corresponding author: ryan.bradley@wits.ac.za
}

(C) Penerbit Universiti Sains Malaysia, 2018. This work is licensed under the terms of the Creative Commons Attribution (CC BY) (http://creativecommons.org/licenses/by/4.0/). 
The aims of this paper are to evaluate the different methodologies currently implemented for the construction of masonry shells, as well as to highlight issues with some of these techniques. Furthermore, several construction considerations are presented to aid in mitigating cracking in low-cost earthen shells. These are based on a review of the literature, as well as experiences gained through the design, construction and monitoring of several earthen model and full-scale shells.

\section{ISSUES WITH CRACKING}

Unreinforced earthen masonry is particularly susceptible to cracking due to its relatively low tensile strength. Furthermore, the formation of cracks, which facilitate moisture ingress, can become hugely problematic if left unrepaired. Several reasons to ensure low-cost earth masonry shells remain crack-free are identified below:

1. Cracking of surface renders and/or the load-bearing earthen masonry itself provide pathways for moisture ingress, which can lead to localised erosion, loss of strength and reduced longevity of the structure.

2. Structures that are extensively cracked and/or poorly built will impact the public's perception of either earthen materials or shell forms: good quality structures are critical to instil confidence in the population. This is particularly important because there is low acceptability of earth building materials amongst most social groups (Adam and Agib, 2001).

3. Due to the negative effects of moisture, cracks may need expensive remedial action, such as the application of sealants and waterproofing membranes, which may be inconsistent with the objectives of a sustainable low-cost solution.

4. Additionally, the accumulation of water within the earthen shells through cracks may lead to health concerns related to persistent damp. This issue can become an acute problem due to the economic constraints of the inhabitants of these low-cost structures (i.e., sometimes repairs are only implemented when resources are available, well after damage has occurred). This issue is apparent in many of the masonry domes at the Sparrow Rainbow Village (an orphanage located in Johannesburg, South Africa): see Figure 1. This issue is echoed further by the presence of plants growing out of cracks in many of the domes. Some of these domes were eventually repaired with relatively expensive waterproofing membranes and paint. 


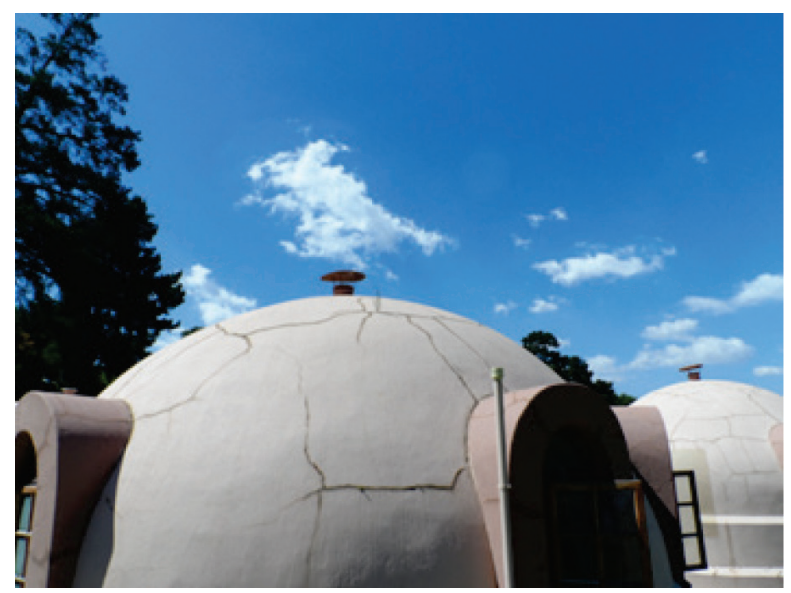

Figure 1. Surface Cracking Over a Dome at the Sparrow Rainbow Village

Due to these above-mentioned issues, designers should attempt to minimise cracking whenever possible.

\section{EARTHEN DOMES AND VAULTS: HOUSING AND RECREATIONAL STRUCTURES}

Earthen building materials have a cultural heritage dating back over 10,000 years (Walker, 2004). Several examples of ancient vaulted masonry, built millennia ago, still exist today. In particular, vaults built over 3,200 years ago are still standing within the temple precincts of Ramses II near Luxor (Minke, 2009). Fathy (1973) describes several mud-brick vaults, over 2,000 years old, situated in the town of Touna el Gabal, Egypt. In his excursion throughout rural Egypt, Hasan Fathy encountered numerous mud-brick vaulted houses in towns such as Gharb Aswan, Fares, and Marg. Egypt, in particular, has a rich history of mud-brick domes and vaults used as roofing elements for housing structures.

Hassan Fathy enhanced the use of these ancient construction techniques (i.e., the Nubian techniques) through several buildings at the village of New Gourna, Egypt (Fathy, 1973). More recently, the Nubian techniques are being used, and adapted, at the Auroville Earth Institute (India) to construct a variety of vaulted low-cost housing and recreational buildings (Auroville Earth Institute, 2016). Vaults spanning up to 10 metres have been built by the Institute. Similarly, the Adobe Alliance (based in in Presidio, Texas) has built several mud brick domes and vaults for housing (www.adobealliance.org).

Several compressed stabilised earth brick (CSEB) shells built in India, Sudan and South Africa highlight the economic benefits of these structures. Adam and Agib (2001) note that the construction of an earth masonry prototype school in Khartoum, Sudan, which resulted in a total cost saving, per square metre, of approximately $40 \%$. CSEB masonry domes and steep vaults, which replace the standard wall and roof, have also shown to be a consistently cheaper alternative than conventional housing structures (Bulovic, 2014; Gohnert and Talocchino, 201 1; Gohnert and Magaia, 2004). 


\section{CONSTRUCTION METHODOLOGIES AND CONSIDERATIONS}

\section{General}

There are a variety of construction methods that have been adopted for the construction of earthen masonry vaults, domes and complex shells. Some of these techniques can be dated back thousands of years where they were used in regions such as Egypt and in the Middle-East (i.e., Nubian construction [Minke, 2009] and building over earth forms [Wilson, 2005]).

There are principally two methodologies adopted for the construction of earthen shells; namely, free-hand (possibly with guide-work) and with formwork. Both require careful consideration during planning and design to ensure that the shells are not damaged during construction. The advantages, concerns and design considerations associated with several classic and contemporary construction methodologies are discussed in the following sections.

\section{CONSTRUCTION WITHOUT FORMWORK}

\section{The Nubian Techniques}

The Nubian techniques are one of the oldest construction methods, which were developed in Upper-Egypt thousands of years ago, for the construction of masonry arches and domes. These methods exploit the surface friction of the blocks and adhesion of the mortar to construct an earth masonry vault without the use of any formwork. Typically, these vaults are built-up with consecutive inclined arches. The angle of inclination of these arches are characteristically between $65^{\circ}$ to $70^{\circ}$ from the horizontal (Minke, 2009). Deviation from this range can result in collapse if the angle is too low, or blocks may fall/slide off if the angle is too high. Furthermore, to prevent sliding during construction, the bricks must be light (such as adobe rich in straw) and not too thick (typically between 5-6 cm) (Houben and Guillaud, 1994). "Nubian-style" domes are also built free-hand with minimal equipment requirements. Traditionally, these domes are built in horizontal courses of adobe blocks: only aided by a marking line attached to the focus of the dome and the mason's wrist (Houben and Guillaud, 1994). Normally, a sticky earthen mortar (i.e., a high clay percentage) is used to prevent the bricks from sliding off the preceding course. Usually light bricks which are raked (or keyed), to improve adherence, are used in this application.

\section{Cupola Tracer}

A number of simple, and rather more complex, tools have been developed for the precise placement (i.e. at the correct position and inclination) of masonry units. The "cupola tracer" is one such device, which enables the rapid construction of brick courses: see Figures 2(a) and 2(b). Gohnert and Magaia (2004) discuss the design and construction of a low-cost CSEB masonry dome built near Maputo, Mozambique, using the "cupola-tracer" technique. The construction of the CSEB dome is shown in Figure 2(a). Magaia (2003) notes, reflecting on the difficulties during construction, that the top closure of the dome is one of the most critical points in this process. Specifically, near the top of the dome the "cupola-tracer" is 
no longer useful, because the adhesion, between CSEB and mortar, is insufficient to prevent the bricks from sliding off. Consequently, the top section had to be built over shaped earth, which required horizontal support through propped formwork. However, some subsidence of the soil occurred near the apex of the dome during the removal of the formwork, which lead to the errors shown in Figure 2(b).

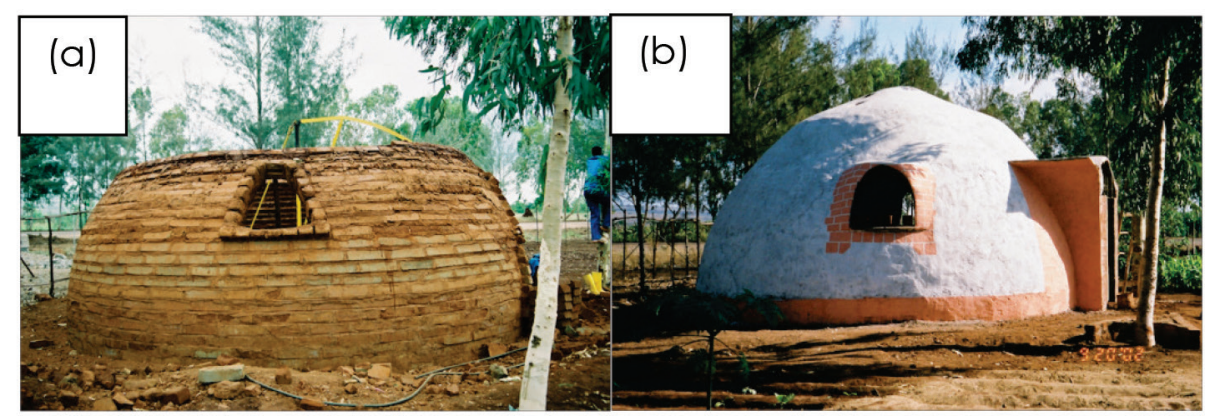

Figure 2. Free-Hand Construction of an Earth Brick Masonry Dome: (a) Construction with Cupola Tracer and (b) Errors at the Apex of the Completed Dome

\section{Timbrel Vaulting}

Timbrel (or Catalan) vaulting is another construction technique which has gained recent revival in significant projects, such as the Mapungubwe Interpretation Centre (Ramage et al., 2010). Timbrel vaulting is a form of construction initially introduced in the 14th century, but not until the 16 th century did it become common practice (Huerta, 2003). The primary advantages of these building techniques are the comparatively cheap building materials, availability of the materials, and the need for only limited light-weight structural formwork/framework. Ochsendorf (2010) notes that such lightweight-framework was popular in North America between year 1880 and 1960, where over 1,000 buildings were constructed by the Guastavino Company. Rafael Guastavino refined the materials and construction practices of Catalan vaulting: his best-known contribution is that of the Cohesive Construction Technique. Guastavino replaced the traditional gypsum mortar with rapidly hardening Portland cement, which enabled the construction of vaults that spanned three to five times the typical span of traditional Catalan vaulting (Tarragó, 2002).

The Mapungubwe shells were built without formwork or centring: construction was done by sighting between completed portions and curved plywood guides (Fitchett, 2009). The first layer of compressed stabilised earth tiles was placed by hand, using rapid setting gypsum (Crystacal). This layer then provides the "formwork" for successive layers, which were laid with typical cement-sand mortar, until the required thickness was achieved. Chothia (2010) and Gohnert et al. (2013) describe the construction of two earth-tile cross-vaults, built at the University of the Witwatersrand, using similar techniques to those used for the construction of the Mapungubwe shells. An image illustrating the free-hand construction of one of these shells is shown in Figure 3. 


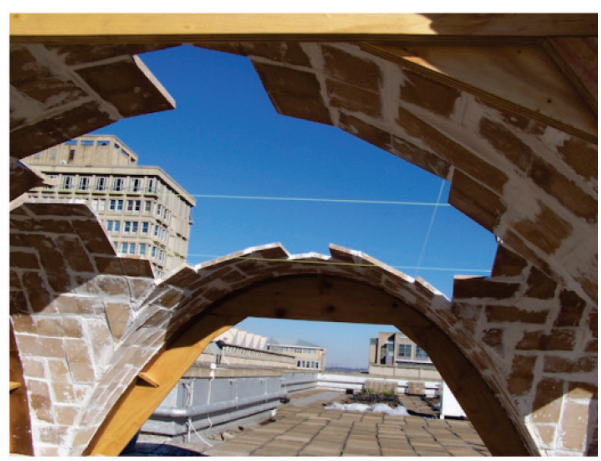

Figure 3. Freehand Construction of an Earth Tile Cross-Vault

When building free-hand, it is extremely important that strict attention is given to the construction accuracy of the earthen shell. Because earthen materials cannot accommodate flexural or tensile stress, overall strength and stability are achieved through geometrical form. Thus, divergence from the required shape may impact the capacity of the shell, possibly leading to cracking or even collapse. Some issues with this construction process are apparent in the Mapungubwe shells: in particular, undulations are apparent in some of the shells: see Figure 4. When utilising freehand construction techniques it is critical that accurate guiding and framework be used. Furthermore, skilled bricklayers should be used to ensure quality construction. However, in many developing countries there is potential to create employment and develop skills during the construction of low-cost housing and recreational structures, which must be recognised. In some projects, employment of community members may be a requirement of the client. Thus, unskilled labour may make up the bulk of the workforce in certain projects.

Nevertheless, the work of Eladio Dieste and Felix Candela, in Uruguay and Mexico respectively, exemplify the use of a largely unskilled labour force to construct complex shell forms (Fitchett, 2009; Pedreschi, 2000; Melaragno, 2012). According to Fitchett (2009), Dieste's use of sophisticated engineering, to allow for simplicity of site operations and supervision of the work by highly trained managers, allowed the majority of the construction work to be undertaken by unskilled labour (often farm workers). Melaragno (2012) notes that Candela successfully attained complex geometric shapes using relatively unskilled labour by having a clear perception of the construction methodology throughout the project. These above-mentioned approaches, employed by Dieste and Candela, are integral to realise the safe and accurate construction of earthen masonry shells - particularly those that are built free hand by unskilled labour.

Another critical aspect is the formulation of a construction sequence that will not generate loading that the partially complete shell cannot sustain. In particular, the loading incurred during construction, when the shell is incomplete, may be much greater than that experienced by the completed structure (i.e., during the construction process the partially complete shell may be unstable, and the erection precarious, until the form is complete). 

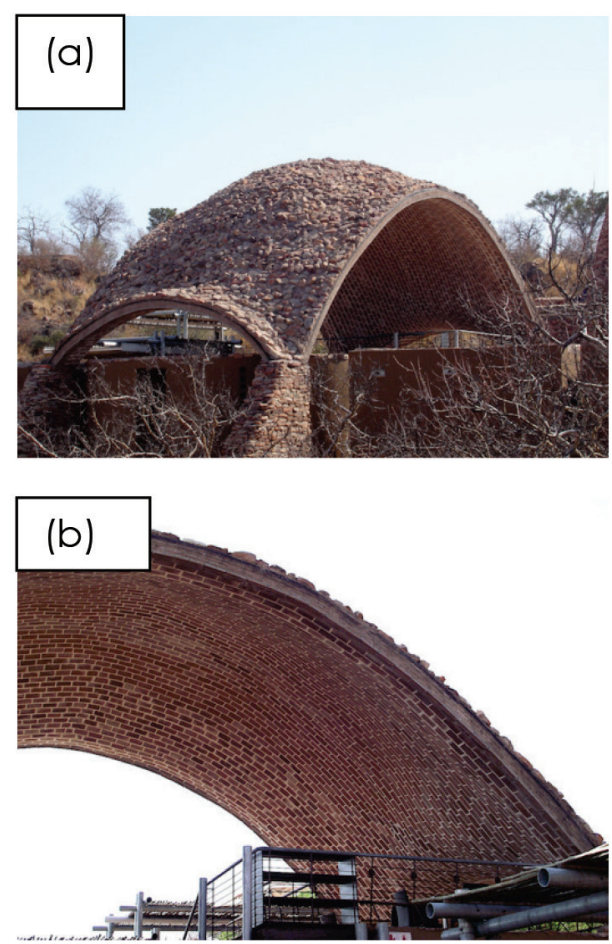

Figure 4. Large Earth Tile Structure: Mapungubwe Interpretation Centre - (a) Large Free-Spanning Shell and (b) Shell Undulations

\section{CONSTRUCTION WITH FORMWORK}

\section{Earth Formwork}

Because the production of typical formwork (i.e., timber boards, steel sheets, etc.) is labour, materials and energy intensive, earth formwork was historically used for the construction of many masonry shells. The use of earth for formwork dates back millennia where it was used by the Egyptians for pyramid construction. Even in modern times, the earth form method offers an economic and versatile solution for the construction of thin shells in certain situations. It has been employed for the construction of masonry domes (see Minke, 2009) as well as several large thin shell concrete structures in recent times. An ice skating rink built in Provo, Utah, is a well-known large reinforced concrete shell structure built with earth formwork (Wilson, 2005). The triaxial elliptical dome is 73 metres long, 49 metres wide, and 12 metres high. The form was made by using approximately 40,000 cubic yards of earth, moulded into the proper shape (Wilson, 2005). This large amount of soil was appropriated from the foundation excavation of a nearby structure which significantly reduced transportation costs. Furthermore, Wilson notes that the operation was greatly simplified by using an earth mound to form the complex dome. However, in many situations the vast amounts of soil required may incur 
significant cost, and, consequently, cheaper techniques such as inflated forms are adopted for these large shells (Wilson, 2005).

The application of this technique to masonry shell construction is relatively simple: moist soil is shaped into a form defining the intrados of the shell and the masonry is subsequently built over this form. Bricks or some other supporting structure can also be used to occupy part of the internal volume in order to limit the amount of soil (and consequently work) required. Figure 5 shows a model catenary dome built using this technique. Moist sand was placed over and around an inverted bucket and shaped with a wooden catenary cut-out to attain the desired shape.

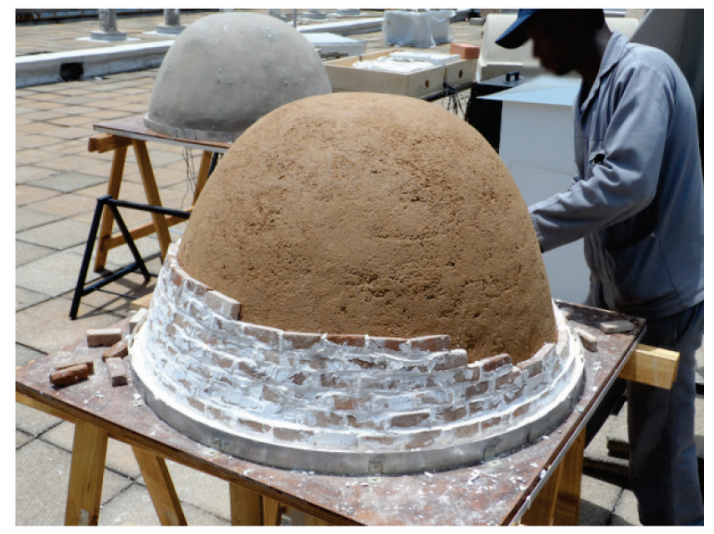

Figure 5. Small Dome Built with Earthen Formwork

The removal of the earth mould requires careful and considered excavation. According to Wilson (2005), soil should be removed from the exact centre of the shell to its outer edges to ensure shell action and prevent the structure's collapse during excavation.

\section{Full Formwork}

In the case of domes and complex earthen shell forms, construction without formwork is preferred since curved formwork is complicated and expensive to manufacture. However, when formwork is utilised it should be light, mobile and easily dismantled to be effective (Houben and Guillaud, 1994). Understandably, formwork also needs to be sufficiently stiff to ensure that it does not warp during construction. Typically, formwork is built from timber boards or metal sheeting, supported by a trussed network.

Although formwork may increase the costs associated with in a one-off construction, the effectiveness of formwork becomes apparent when multiple shells forms of similar geometry need to be built. Felix Candela's work, in particular, demonstrates the effectiveness of reusing formwork (The success of his construction company came largely through designing reinforced concrete thin-shells that allowed for the re-use of formwork from previous projects, which expedited construction and greatly reduced materials costs). According to Melaragno (2012), the re-use of formwork has produced extraordinary cost reductions in the construction of concrete thin shells. 
Another advantage of adopting prefabricated formwork is that its use may greatly improve the accuracy of construction; however, accurate formwork alone does not guarantee a high quality of work. Figure 6 shows the first segment of a vault built with formwork at the University of the Witwatersrand. The vault was built by bricklayers accustomed to typical vertical wall construction, and consequently this "unusual" technique required some practice in order to lessen the chance of mistakes. One such mistake (i.e., a kink) is clearly apparent in Figure 6. At times, several layers of bricks had to be removed and rebuilt to rectify these errors. These initial segments came to be a learning experience for the bricklayers, and the remaining work, in the most part, was completed quickly and accurately. These lessons highlighted the importance of experience (and skill), as well as the need for continuous monitoring to ensure that any inaccuracies in the form are identified immediately, before significant remedial action is required.

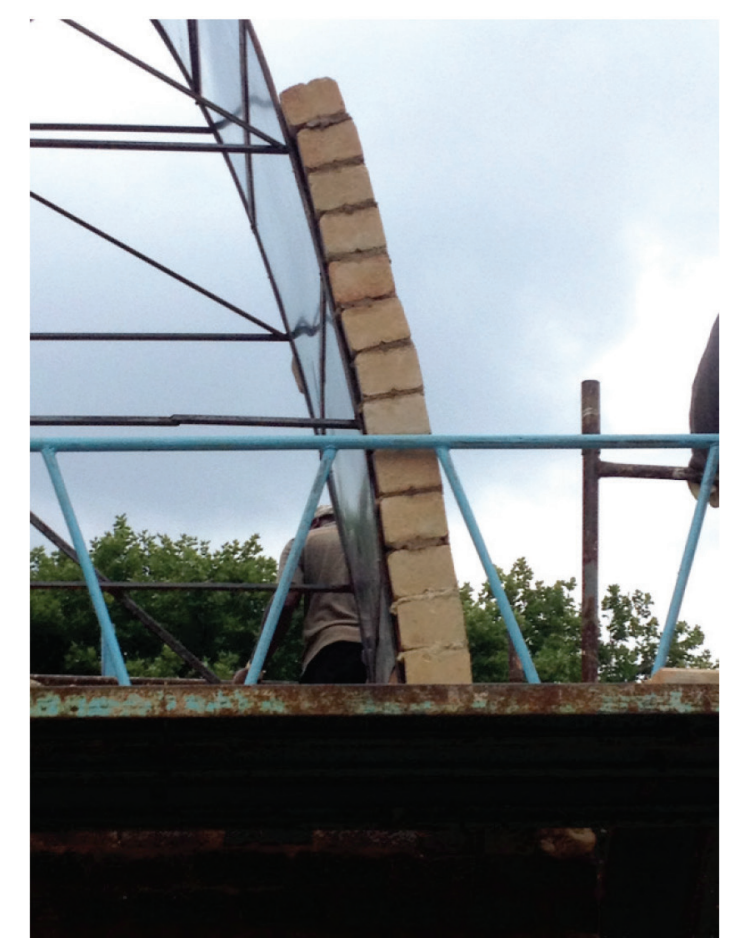

Figure 6. Issues with the Construction of the Wits Shells

Additionally, when masonry shells are built with rigid formwork they may be vulnerable to cracking after the final bricks are laid. The shell will contract, due to shrinkage (e.g. drying and/or vertical) of the mortar, which is opposed by the rigid formwork. This type of cracking was observed during the construction of two steep catenary vaults built at the University of the Witwatersrand (Wits). In the case of vaulted structures, these cracks typically manifest towards the apex of the shell if shrinkage is restrained - as discussed in Bradley et al. (2016). To eliminate cracking in 
the remaining segments, the mortar was allowed an initial set before the formwork was dropped and the vault was able to dry unrestrained.

Several small-scale earth-brick vaults were built to explore the cause of cracking observed in the Wits shells. The materials used to build the model were compressed cement stabilised earth tiles and class II mortar (as specified in BS 5628): see Figure 7(a). Two distinct setups were adopted: namely, (1) formwork left in place overnight and (2) formwork dropped after the initial set of the mortar (typically 90 minutes after construction had been completed). The following day, longitudinal cracks, through the entire thickness and along the apex, were only present in vaults in which formwork was left in place. An apex crack observed in one of these models is shown in Figure 7 (b) (internal surface).
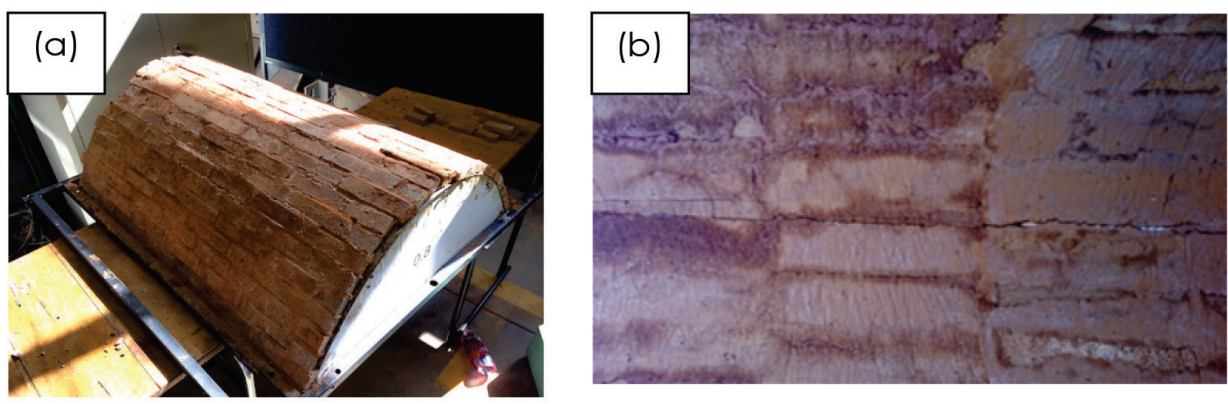

Figure 7. Model Catenary Vaults Built Over Rigid Formwork: (a) Shrinkage Prevented by Rigid Formwork and (b) Apex Crack (Internal Surface)

To avoid such cracks, formwork must be removed just after the initial set of the mortar. However, it must first be established that the mortar has set sufficiently to accommodate load transfer between adjacent bricks. If the formwork is dropped prematurely, or the stiffness of formwork is inadequate, the likelihood of distortions or even collapse will increase.

\section{Inflatable formwork}

Another notable technique incorporates the use of inflatable-formwork. This system has become very popular in recent years for the construction of a variety of thin shell structures. Wilson (2005) notes that during the past few years, more than 2,000 structures have been built throughout the world by the inflatable formwork method. Furthermore, inflated forms can be used to create shells with unusual shapes.

The forming system incorporates an inflatable fabric structure, typically made of PVC coated nylon or polyester fabrics. The primary application of this system is for sprayed concrete (i.e., shotcrete). The shell may be constructed from either the inside or outside; however, most of the shells built using the inflatable formwork technique have been built from the inside (Wilson, 2005). This option is preferred because construction can be accomplished in all forms of weather, the internal atmosphere is controlled and curing conditions are perfect. An airlock, however, is required for workers to enter the inflated form which may not be economical for smaller structures. 
Although this method has been widely adopted for the construction of small to very large concrete shell structures, it has only recently been utilised for standard (e.g., fired clay or cement brick) and earth masonry structures. Numerous cementbrick masonry domes were successfully built by Dome Space (South Africa) using inflatable formwork at the Sparrow Rainbow Village, Johannesburg (Talocchino, 2005). Understandably, due to the different building requirements for masonry, when compared with shotcrete, construction of masonry domes takes place from the outside. Gohnert and Talocchino (2011) discuss the use of this method to construct a small low-cost earth-brick dome at the Central Johannesburg College (CJC): see Figure 8. A major advantage of this formwork is that it can be deflated and reused, making it a very economical and efficient option if many similar structures are to be built. Such formwork also facilitates rapid construction; the dome at CJC was built in only two days. Furthermore, the form is very flexible, making it more accommodating to shrinkage (when compared with the more typical rigid types of formwork).

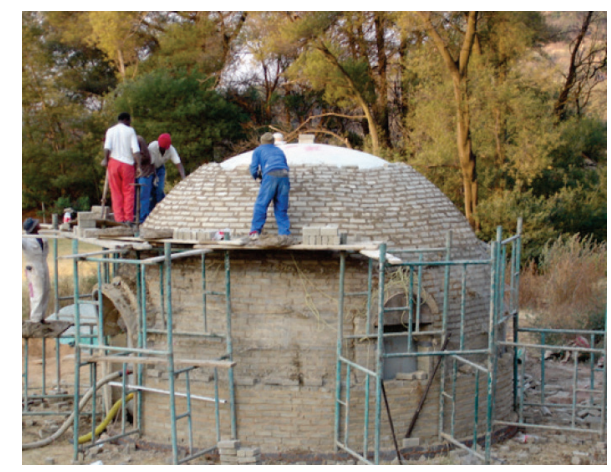

Figure 8. Construction of a Masonry Dome with Inflatable Formwork

\section{Shifting Formwork Technique}

When adopting the sliding technique, only a small segment of formwork is used instead of continuous formwork. Construction takes place sequentially, as the formwork is shifted to create the barrel vault. The technique is relatively cheap because only a short piece of singly curved formwork needs to be manufactured. This construction technique was used to build two steep catenary vaults at the University of the Witwatersrand (Bulovic, 2014), as shown in Figure 9. 


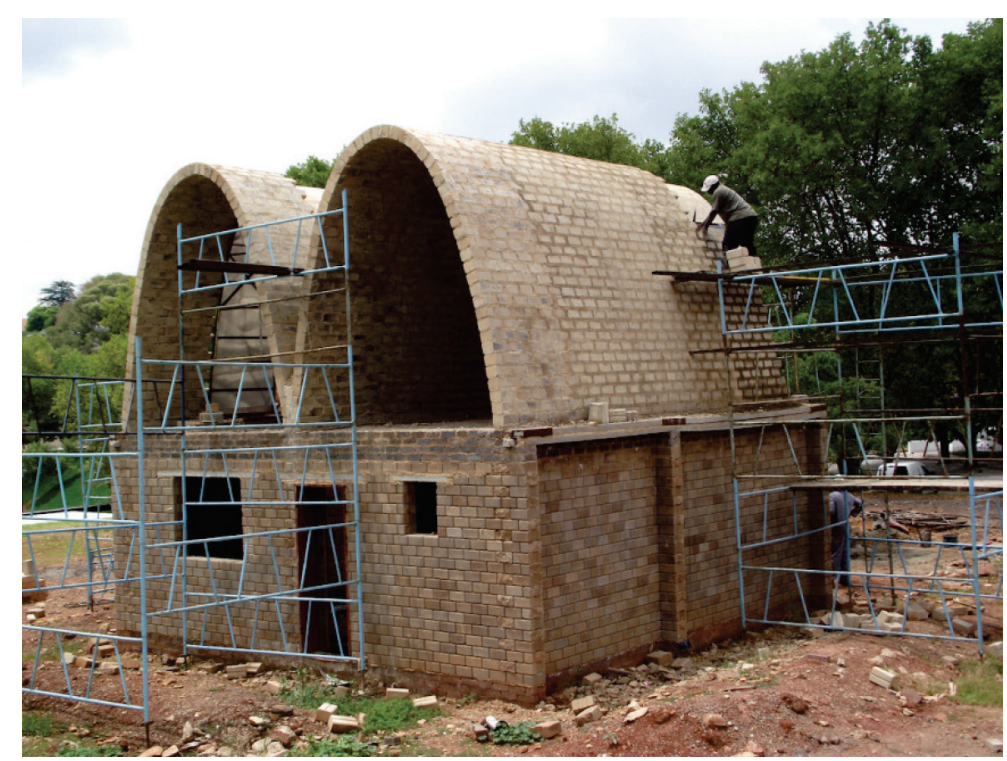

Figure 9. Construction of the Wits Shells

The shifting technique is mentioned in several books (e.g., Joffroy and Guillaud, 1994; Minke, 2009) however, no information of any problems associated with this method could be found in the literature apart from Bradley et al. (2016). Bradley et al. attribute several vertical cracks, observed on the external and internal surface of two steep catenary vaults, to differential shrinkage between adjacent segments and consequently the generation of restraint. One of these cracks is shown in Figure 10.

Shrinkage in an earthen shell will typically be localised to the joints if the bricks/blocks have been given sufficient time to cure prior to construction. Morton (2008) notes that a wall, comprised of earth bricks and $10 \mathrm{~mm}$ clay mortar joints, will typically shrink between $0.0004 \%-0.002 \%$. However, vertical shrinkage of the joints under load is greater, typically, $0.01 \%-0.05 \%$, and can be increased more by slump (Morton, 2008). Considering these above-mentioned values, it is apparent that vertical shrinkage may be as much as 25 times greater than drying shrinkage. 


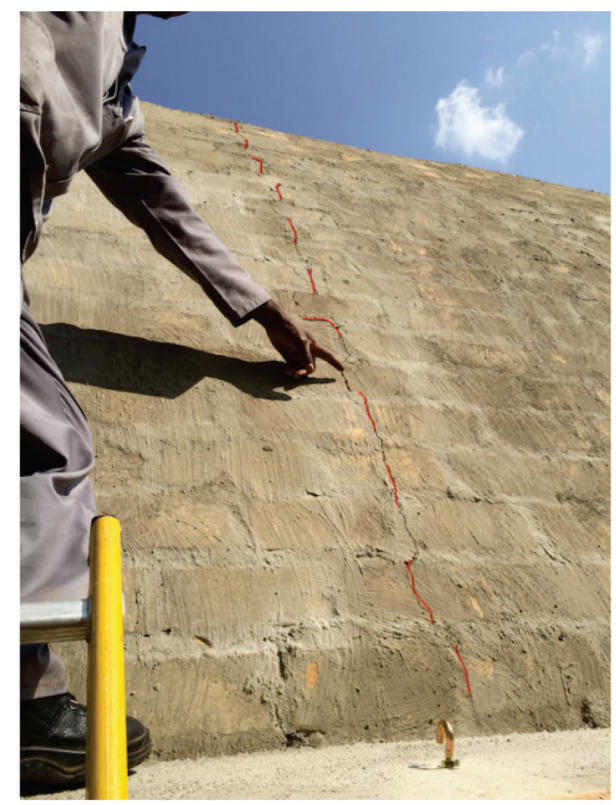

Figure 10. Crack at the Interface Location (Crack Traced in Red for Clarity)

It is postulated that shrinkage in the Wits shells may have been compounded due to two characteristics associated with the adopted construction method, namely:

1. Steeper vaults built with formwork will experience greater vertical shrinkage than a shallower vault under load. This is fundamentally due to the slope of the shell (i.e., a steep vault will carry much of the load internally, and therefore transfer less load to the supporting formwork). This is illustrated by the fact that the formwork used at Wits worked very effectively, without the need for excessive stiffening - the sparsity of the formwork is apparent in Figures 6 and 9.

2. The mortar joints in the Wits shells had to be fairly large $(\approx 25 \mathrm{~mm})$ to allow the next arch/segment enough space to key into the previous segment. Larger joints will increase the total shrinkage during drying out after building work, which will magnify stress concentrations.

Although the explanation for the cause of these cracks appears rational, a simple analysis using finite elements (FE) is considered for further assessment. A finite element package was used to create a model of a steep free-standing catenary vault: see Figure 11 (a). Eight-node quadrilateral shell elements, and a regular/structured mesh, were utilised in the analysis. The material and geometric properties implemented in this simple assessment are shown in Table 1 (Material isotropy was assumed and the appropriate properties for CSEB were adopted from Magaia [2003]). 
Table 1. FE Model Properties
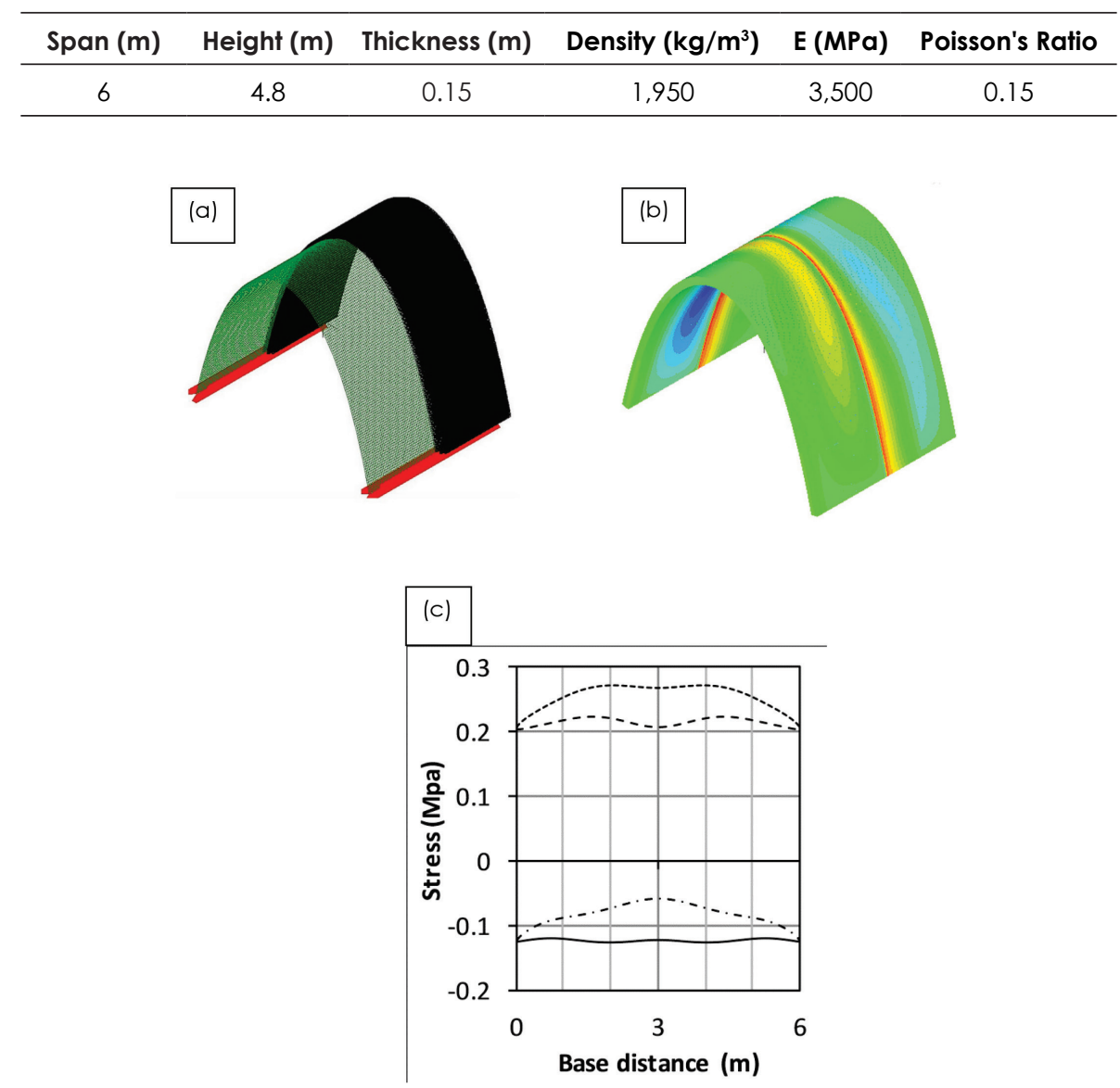

Figure 11. FE Model and Results: (a) $20^{\circ} \mathrm{C}$ Temperature Drop Over Half of the Structure, (b) Minor Principal Stress Upper and Lower Surface and (c) Principal Stresses: Pinned Boundary Conditions

Initially, the element mesh was refined, for self-weight loading, until the model converged to the exact/closed-form solution. Subsequently, thermal contraction (created by applying a temperature differential to the shell) was used to simulate shrinkage. In particular, a drop in temperature was applied to one half of the shell only (as shown by the black region in Figure 11[a]); to simulate the effects of different rates of shrinkage in adjacent sections of a vault. The calculation of the temperature differential $(\Delta \mathrm{T})$ and coefficient of linear expansion $(\alpha)$, to roughly simulate shrinkage, are discussed below.

A vertical shrinkage of $0.03 \%$, which falls within the characteristic range for 10 $\mathrm{mm}$ joints as noted by Morton (2008), was selected for the analysis. By adopting an arbitrary linear element of masonry, the corresponding shrinkage strain is expressed in Equation 1: 


$$
\begin{aligned}
\text { Strain } & =0.03 \div 100=0.0003 \mathrm{~m} / \mathrm{m} \\
& =300 \mu \varepsilon
\end{aligned}
$$

For the purposes of this simple simulation, a $20^{\circ} \mathrm{C}$ temperature drop $(\Delta \mathrm{T})$ and coefficient of linear expansion of $0.015 \mathrm{~mm} / \mathrm{m}^{\circ} \mathrm{C}(\alpha)$ provide a thermal strain which matches that given by Equation 1: see Equation 2 (as before, this strain value corresponds to a linear element).

$$
\begin{aligned}
\text { Strain } & =\alpha \mathrm{dT}=20^{\circ} \mathrm{C} \times 0.000015 \mathrm{~m} / \mathrm{m}^{\circ} \mathrm{C}=0.0003 \mathrm{~m} / \mathrm{m} \\
& =300 \mu \varepsilon
\end{aligned}
$$

Figure $11(\mathrm{~b})$ shows the internal and external minor principal stress contour plots corresponding to pinned boundary conditions. A damp-roof course (DPC), situated at the base of the shell, would engender a pin (or sliding) support. The arrows in black show the direction of these stresses at the interface. It is apparent in the plot that maximum tensile stresses, identified by warm colours (i.e., red), are localised along the interface (i.e., along the centreline). These major and minor principal stresses along the centreline of the vault are shown, for pinned boundary conditions, in Figure 11 (c). This figure demonstrates that the major principal stresses are purely compressive; however, the minor principal stresses are entirely tensile at the inner and outer faces. Tensile stresses also exist when the support condition is changed to fixed (i.e., an infinitely stiff support): not shown in this paper. Although this analysis is somewhat simple, the maximum tensile stresses coincide exactly with the observed cracking in the Wits shells, which gives support to the postulate for cracking proposed by Bradley et al. (2016).

The vertical cracking observed in the Wits shells signifies a shortcoming of the shifting-formwork technique. It further highlights the importance of the mortar joint characteristics and the construction scheme (or progression). If the shifting method is to be used for steep profiles, such as those built at Wits, the following should be considered:

1. Firstly, there should be an understanding that any fixity created during construction will likely result in cracking damage due to the inevitable shrinkage of the mortar. Thus, the design should accommodate any differential movement between dissimilar materials or parts of the structure (i.e., the shell should be designed so that shrinkage and the resulting stresses are not focused in a particular region).

2. Thinner joints, which are less susceptible to shrinkage, should be used whenever possible. Very thin joints should, however, be avoided as capillary suction can induce rapid drying and possible weakening of the brick-mortar bond. Furthermore, acceptable jointing of segments becomes problematic with thin joints when using the conventional shifting technique.

3. Due consideration should be given to the material and shrinkage properties of the mortar mix. Typical linear shrinkage of earthen mortar should be between $1 \%$ to $5 \%$ (Morton, 2008). Some national standards also provide limits on linear shrinkage (i.e., the New Zealand Standard 4298 [1998] stipulates a linear shrinkage limit of $3 \%$ for earthen mortars). 


\section{CONCLUSIONS}

In this paper, several construction methodologies were reviewed. Several recommendations, particularly in relation to the prevention/mitigation of cracking, derived from this study are presented below.

\section{Free-Hand Construction}

When adopting free-hand construction techniques there should be constant monitoring of the in-situ shell geometry to ensure that it meets the design specifications. Because pure-compression shells derive strength and stability from their geometry, even small variations in shape can cause unintended bending or tensile stresses that may result in cracking. Thus, it is recommended that skilled bricklayers should be used when building free-spanning earthen shells without formwork. Typically, free hand construction is restricted to certain building unit types such as multiple layers of earthen tiles or small light-weight earthen blocks. Freehand construction using CSEB is far more challenging, particularly when building shallow portions of shells.

\section{Construction with Formwork}

The use of formwork will typically increase the cost of a one-off earth masonry shell construction. In some cases, formwork may need to be fabricated to complicated forms, particularly for complex double-curvature shells. Formwork is also typically made from materials which are either expensive and/or energy intensive (i.e., steel sheeting over a timber/steel supporting trusses). Due to these considerations, freehand techniques are often more appealing to designers for the construction of complex shells, such as the shells of the Mapungubwe Interpretation Centre.

Although formwork is an added cost, its use may, in some cases, greatly improve economy - especially when building multiple shells of the same form such as in low-cost housing developments. In particular, the use of reusable formwork may greatly reduce labour costs due to improved speed of construction, and may also lessen the likelihood or construction errors, possible damage and the consequent increased time and costs associated with repairs and re-work.

Formwork itself can create problems during construction due to the restraint it might generate whilst the mortar between units shrinks. Thus, the construction sequence is critical to ensure that fixity is not generated, which will inevitably result in cracking damage. This issue is particularly evident in shells which experience vertical shrinkage from settling of the joints under load, which can be much larger than drying shrinkage.

\section{ACKNOWLEDGEMENTS}

The authors gratefully acknowledge the contribution of Hydraform, who donated the earth bricks and tiles used in several of the constructions discussed in this paper. Construction work was carried out with assistance of Mr Henrique Licotso. We also greatly acknowledge the comments by Dr Anne Fitchett that assisted in improving this manuscript. 


\section{REFERENCES}

Auroville Earth Institute (2016). Construction Projects. Tamil Nadu, India: Auroville Earth Institute. Available at: http://www.earth-auroville.com/construction projects_en.php [Accessed on 27 October 2016].

Adam E.A. and Agib A.R.A. (2001). Compressed Stabilised Earth Block Manufacture in Sudan. Paris: United Nations Educational, Scientific and Cultural Organization (UNESCO).

Bradley, R.A., Gohnert, M., Bulovic, I., Goliger, A.M. and Surat, D.B. (2016). Steep catenary earth-brick shells as a low-cost housing solution. Journal of Architectural Engineering, 23(2): 04016018. https://doi.org/10.1061/(ASCE) AE.1943-5568.0000234.

British Standards Institution (2005). BS 5628:2005 Code of Practice for the Use of Masonry: Materials and Components, Design and Workmanship. London: British Standards Institution.

Bulovic, I. (2014). Catenary vaults: A solution to low-cost housing in South Africa. MSC diss. University of the Witwatersrand.

Chothia, A. (2010). An investigation into the thermal effects on a double groin vault. BSc project report. University of the Witwatersrand.

Fathy, H. (1973). Architecture for the Poor: An Experiment in Rural Egypt. Chicago: The University of Chicago Press. https://doi.org/10.7208/ chicago/9780226239149.001.0001.

Fitchett, A. (2009a). Timbrel vaults from stabilized earth tile. Proceedings: 11th International Conference on Non-Conventional Materials and Technologies. Bath, UK: University of Bath.

Fitchett, A. (2009b). Skills development and employment creation through small public buildings in South Africa. PhD diss. University of the Witwatersrand.

Gohnert, M. and Magaia, S.J. (2004). Design and construction of an earth brick dome used for low-cost housing. Journal of South African Institute of Civil Engineering, 46(2): 9-14.

Gohnert, M. and Talocchino, G. (2011). Thin shell masonry domes for low-cost housing. Journal of the International Association for Shell and Spatial Structures, 52(1): 55-61.

Gohnert, M., Fitchett, A., Bulovic, I. and Bhikhoo, N. (2013). Structurally efficient housing incorporating natural forms. Journal of the South African Institution of Civil Engineering, 55(3): 96-102.

Houben, H. and Guillaud, H. (1994). Earth Construction: A Comprehensive Guide. London: Intermediate Technology Publications.

Huerta, S. (2003). The mechanics of timbrel vaults: A historical outline. In A. Becchi, M. Corradi, F. Foce and O. Pedemonte (eds.). Essays on the History of Mechanics. Basel, Switzerland: Birkhäuser, 89-134. https://doi.org/10.1007/978-3-03488091-6_5.

Joffroy, T. and Guillaud, H. (1994). The Basics of Building with Arches, Vaults and Cupolas. St Gallen, Switzerland: Swiss Center for Development Cooperation in Technology and Management.

Magaia, S. (2003). Domes in low-cost housing. MSc diss. University of the Witwatersrand.

Minke, G. (2009). Building with Earth: Design and Technology of a Sustainable Architecture. 2nd Ed. Basel, Switzerland: Birkhäuser. https://doi. org/10.1515/9783034612623. 
Melaragno, M. (2012). An Introduction to Shell Structures: The Art and Science of Vaulting. New York: Springer US.

Morton, T. (2008). Earth Masonry: Design and Construction Guidelines. Berkshire: IHS BRE Press.

Ochsendorf, J. (2010). Guastavino Vaulting: The Art of Structural Tiling. New York: Princeton Architectural Press.

Pedreschi, R. (2000). The Engineer's Contribution to Contemporary Architecture: Eladio Dieste. London: Thomas Telford Ltd.

Ramage, M.H., Ochsendorf, J., Rich, P., Bellamy, J.K. and Block, P. (2010). Design and construction of the Mapungubwe National Park Interpretive Centre, South Africa. ATDF Journal, 7(1/2): 14-23.

Standards New Zealand (1998). NZS 4298 Materials and Workmanship for Earth Buildings. Wellington, New Zealand: Standards New Zealand.

Talocchino, G. (2005). Design and construction criteria for domes in low-cost housing. MSc diss. University of the Witwatersrand.

Tarragó, S. (2002). Guastavino Company (1885-1962): Catalogue of Works in Catalonia and America. Barcelona: Collegi d'Arquitectes de Catalunya.

The Adobe Alliance (2016). Homepage. Available at: www.adobealliance.org [Accessed on 27 January 2017].

Walker, P.J. (2004). Strength and erosion characteristics of earth blocks and earth block masonry. Journal of Materials in Civil Engineering, 16(5): 497-504. https:// doi.org/10.1061/(ASCE)0899-1561(2004)16:5(497).

Wilson, A. (2005). Practical Design of Concrete Shells. Texas: Monolithic Dome Institute. 